\title{
WAVE PREDICTIONS AT THE SITE OF A WAVE ENERGY CONVERSION ARRAY
}

\author{
Jeffrey A. Oskamp ${ }^{1}$ and H. Tuba, Özkan-Haller ${ }^{2}$
}

\begin{abstract}
The SWAN spectral wave model was applied to a domain along the coast of Oregon State, USA with the purpose of establishing a better understanding of wave conditions at a location which has been proposed for the installation of an array of Wave Energy Converters (WECs). The model uses the directional spectrum measured at a nearby NDBC (National Data Buoy Center) buoy as input and in situ measurements of waves at the proposed WEC location for model validation. It was found that wind-wave generation and bottom friction were not significant over the domain between the NDBC buoy and the WEC site (domain size was $30 \mathrm{~km}$ in the cross-shore and $230 \mathrm{~km}$ in the along-shore directions). The predicted wave heights at the WEC location compared favorably to the in situ data wave heights with rms error of $\sim 10$ percent. It is suggested that some of this error may arise from the offshore boundary condition where the waves are assumed to be along-shore uniform. Future work is proposed to address this issue. Future work will also include modeling in two other domains, one very small domain to resolve individual WECs and a domain between the WECs and the shore to assess the impact of WECs on the coastline.
\end{abstract}

Keywords: SWAN; Wave Energy Converters; Wave Modeling

\section{INTRODUCTION}

It is critical to understand the wave conditions at a Wave Energy Converter (WEC) for three reasons. First, understanding wave conditions is necessary for choosing a good location. In the United States, WECs are being proposed for locations within 3 miles of the coastline in water depth less than $50 \mathrm{~m}$. A substantial amount of refraction may have affected the waves before arriving at these water depths; therefore, substantial alongshore variability of the wave conditions in these regions is expected. By predicting the wave conditions along a coastline, it is possible to optimize the placement of WECs. The second reason for understanding the local wave conditions is to design or tune the WEC to be more efficient in a specific location. Depending on the device, there may be various levels of tuning, from changing device characteristics before installation to tuning on hourly timescales to active tuning on the time scale of wave groups (Yavuz et al, 2006). They all aim at maximizing the power output of the device. Third, after a WEC array is installed and connected to the local grid, forecasted power output will aid in the smooth integration of the generated power to the overall electrical grid. For a given device, power output is controlled by the waves, therefore understanding the wave conditions will be critical for supplying these power estimates.

A further goal of this research is to quantify the effects of WECs on the wave field incident on the coastline. This knowledge is a critical first step to assess the likelihood that WECs cause substantial changes in the shoreline configuration on nearby beaches. To model the waves approaching the shore past an array of WECs, we break the problem into three domains (figure 1). The first domain is the domain used in this paper for predicting wave conditions at the WEC site. The results from this domain serve as input into a smaller nested domain containing the WEC array. This domain of the model characterizes the dissipation of wave energy and should simulate some level of the wave structure interaction problem. The wave conditions along the shore-side of this small domain are used as input into another domain that covers the remaining distance to the coast. The waves along the coastline in this model may be compared the waves predicted by a similar model without the WEC array. This gives an estimate of the changes caused by the WECs.

A similar method was implemented along a coastline in the UK (Millar et al, 2007). Using the SWAN (Simulating WAves Nearshore) (Booij et al, 1999), this study designated one partially transmitting obstacle (much like domain 2 above) which represented arrays of WECs. This approach characterized energy absorption as uniform over a large region, allowing for preliminary shoreline effects to be analyzed. Representing an array as a uniform area of dissipation may be a good first approximation for a large array; however, the effects of individual devices will likely prove to be important, requiring the use of a higher resolution model in the vicinity of the devices. Another study modeling shoreline effects of WECs (Palha et al, 2010) was carried out using REFDIF (Dalrymple and

${ }^{1}$ oskampi@coas.oregonstate.edu School of Civil and Construction Engineering, Oregon State University, 104 COAS Admin Bldg. Corvallis, OR 97331, USA

2 College of Oceanic and Atmospheric Sciences, Oregon State University, 104 COAS Admin BIdg. Corvallis, OR 97331, USA 
Kirby, 1991). In this study, power absorption estimates of an attenuator type device were used to determine the energy absorbed by the model in different wave conditions. Their model also avoided resolving the geometry of individual devices, applying absorption coefficients over rectangular regions representing WEC arrays. Yet another study does resolve individual WEC devices (Beels et al, 2010 $\mathrm{a} \& \mathrm{~b})$ and uses the mild-slope equations to model the wave field around a small array of Wave Dragon WECs (Kofoed et al, 2006). The model uses coefficients measured off a prototype device; however, this approach still avoids the full 2-way wave structure interaction problem.

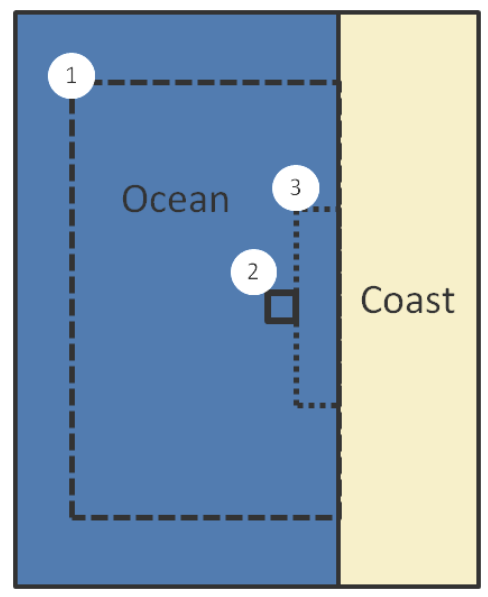

Figure 1 Three domain approach for modeling effects of WECs along a coastline.

The approach proposed here uses components of these previous studies, but suggests that by nesting we may increase the computational efficiency around the devices and resolve the wake of each device interacting with the other devices.

\section{Wave Energy Resource and the Oregon Coast}

The global wave energy resource is distributed unevenly over the beaches of the world (Mørk et. al 2010), and the northwestern coast of North America is an area with comparatively high wave energy. The annual average wave energy incident along the Oregon coast is between forty and sixty kilowatts per meter of wave crest. Understandably, the Oregon coastline has attracted attention for this, and a few companies are taking steps to use this resource.

This study is focuses on one location on the Oregon coast currently being considered as the site of a small array of WECs. The location is shown on a map of the Oregon coastline in figure 2. The model domain (figure 2) extends $270 \mathrm{~km}$ north-south and $86 \mathrm{~km}$ off the coast. This fairly narrow domain is sufficient because $80 \mathrm{~km}$ takes the domain out to the edge of the shelf where the waves are in deep water.

There are several notable features in the domain (see figure $2 b$ ).

- The location proposed for WECs is near the coastline in the center of the domain. During the fall of 2009, an acoustic wave and current meter (AWAC) was deployed at this location and collected 2.5 months of hourly directional wave data. These data are used in this study to validate the model.

- The $200 \mathrm{~m}$ depth contour (drawn darker) shows where $15 \mathrm{~s}$ (or longer) waves begin to feel the bottom. Because of this, some of the longer spectral components incident on the WEC location from the north may be refracted by the shallower depths of Stonewall Bank and Heceta Bank.

- Directly seaward (26km) of the WEC location is NDBC buoy 46229. This buoy collects directional wave data (in 190m water depth), providing another point for model validation or input.

- To the south, Cape Blanco projects westward, providing a potential obstacle for waves incident on the WEC location from the south. 

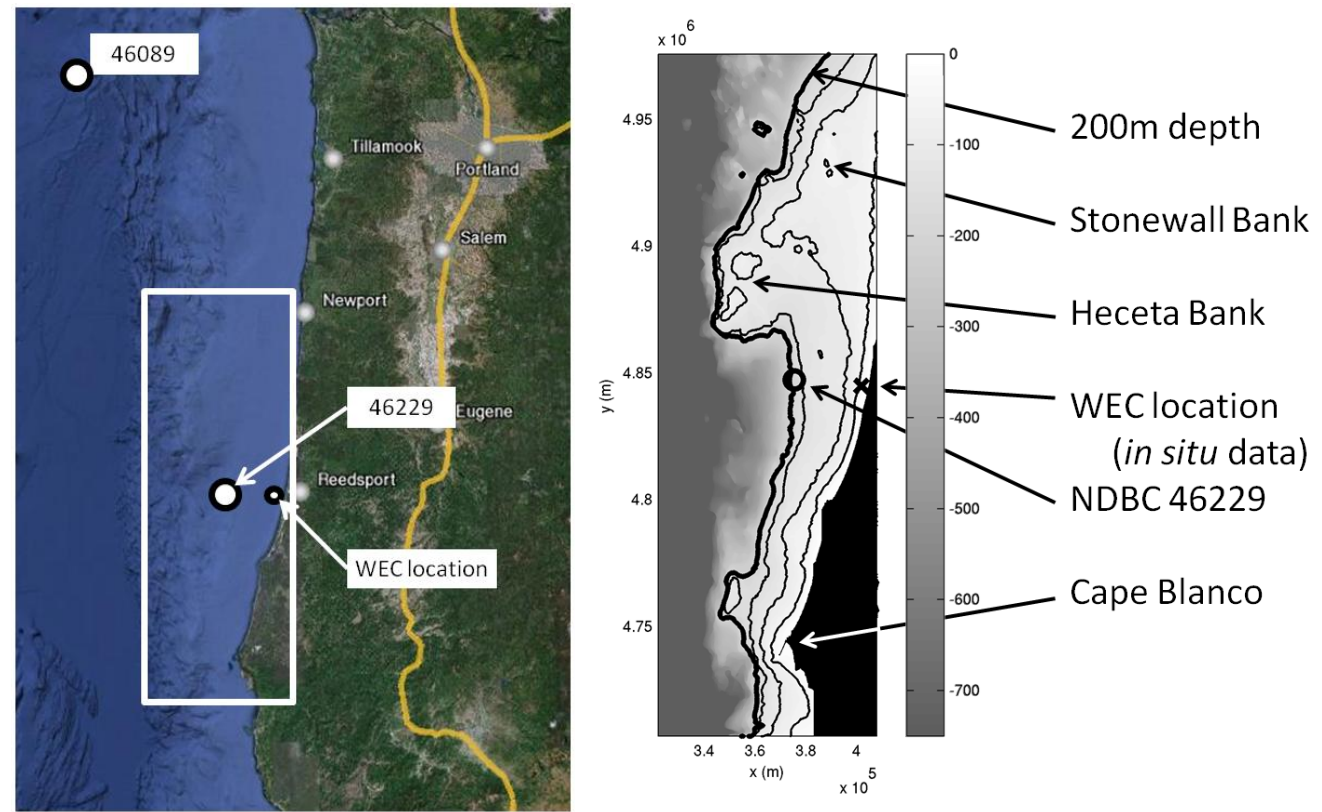

Figure 2 Left: Model domain outlined on the Oregon coast. Data buoys $46089 \& 46229$ are shown for reference as well as the proposed WEC location. Right: Bathymetry in modeling domain: ' $O$ ' = NDBC buoy 46229; ' $X$ ' = proposed WEC location; isobaths drawn at $50 \mathrm{~m}$ increments with $200 \mathrm{~m}$ isobath drawn darker to show where longer waves enter intermediate water; Cape Blanco protrudes west toward the south of the domain.

\section{THE MODEL}

This study implements the SWAN model, a spectral wave refraction model (Booij et al, 1999). The plots shown in this paper assume no wind wave generation within the domain and no bottom friction. These two assumptions are reasonable, because the domain is narrow leaving a small fetch and the shelf is narrow and steep giving bottom friction little time to dissipate energy before the waves break on the shore. Both of these assumptions were tested by running a time series including these effects and comparing results. It was found that the contributions of bottom friction and wind stress are not significant in this domain.
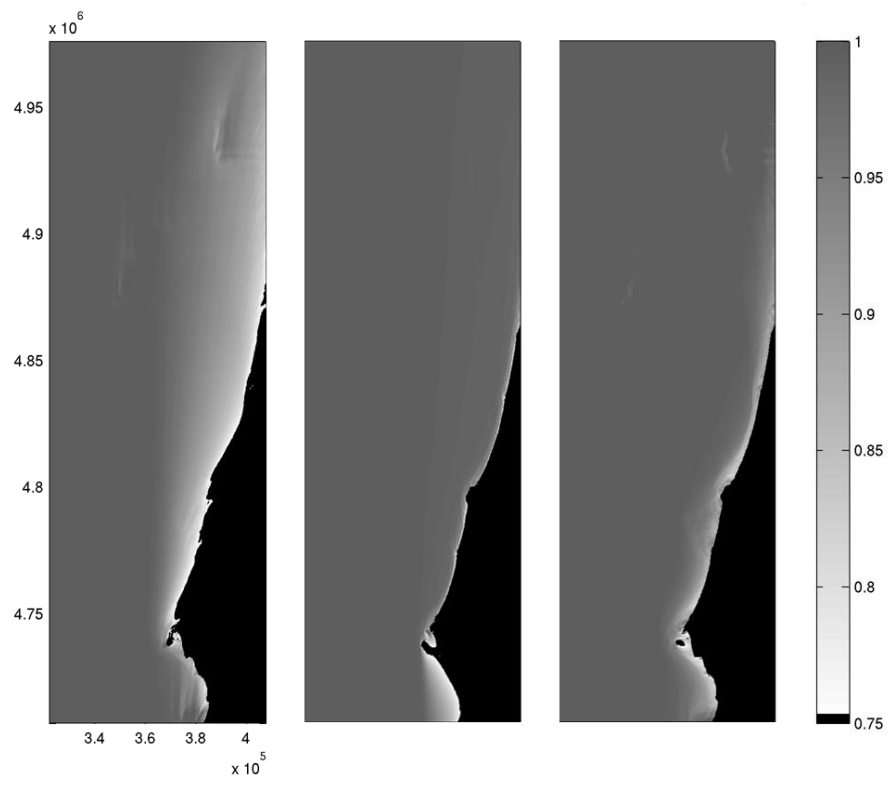

Figure 3 Wave heights for typical wave conditions normalized by the offshore wave height. Left: swell from south; middle: swell from north; right: local sea from west. 
It was mentioned that the waves along the Oregon coast are very energetic. This being true, the wave climate is far from uniform throughout the year (Lenee-Bluhm, 2010). Peak periods vary from 5 to 20 seconds, significant wave heights from 0.5 to $10 \mathrm{~m}$, and mean incident directions between $200^{\circ}$ and $340^{\circ}$ (azimuth). With such variation, it is helpful to select a few of the most typical conditions to examine the type of behavior we should expect to see within this domain. Figure 3 shows the wave heights calculated by SWAN across this domain for three typical conditions: a 15 second swell from the southwest (left), a 12 second swell from the northwest (middle), and a 6 second sea wave from the west (right). These wave heights have been normalized by the offshore wave height. For the SW swell (left), the wave height tapers as you approach the coast North of Cape Blanco. Similarly, for the NW swell (middle), a shadow may be seen below Cape Blanco, while waves arriving from the west are affected little by the cape. Compared to the SW swell, the other waves remain constant in height across portion of the domain near the proposed WEC location. Even for the NW swell, the effects of Stonewall and Heceta Bank seem minimal when compared with the effects of Cape Blanco. This is worth noting, because the proposed WEC location is in this "shadow" area when waves arrive from the south.

\section{Model Input}

To initialize the model, relevant wave spectra are needed to force the offshore boundary. Ideally, this would be a nearby data buoy in deep water. The domain extends out into deep water, so it is reasonable to assume a constant condition along that boundary. In our case, this option was not available. Figure $2 \mathrm{a}$ shows that the nearest deep water buoy is NDBC 46089 . This is located $200 \mathrm{~km}$ north of the domain, quite possibly too far to for this domain. Also, this buoy was not functioning during the time the AWAC data was collected at the WEC location. The other buoy that could possibly be used as input is NDBC 46229. If this buoy was used as the offshore condition, the domain would be cut as in figure 4a. The problem with using 46229 is that its water depth $(190 \mathrm{~m})$ does not meet the conditions for deep water assumptions for the entire spectrum. Figure $4 \mathrm{~b}$ shows the depth along this new offshore boundary. The depth along this boundary is not constant, so using the data from 46229 would be a reasonable condition near that point on the boundary, but because of the varying bathymetry, the assumption that the waves are constant over this boundary may not be valid.
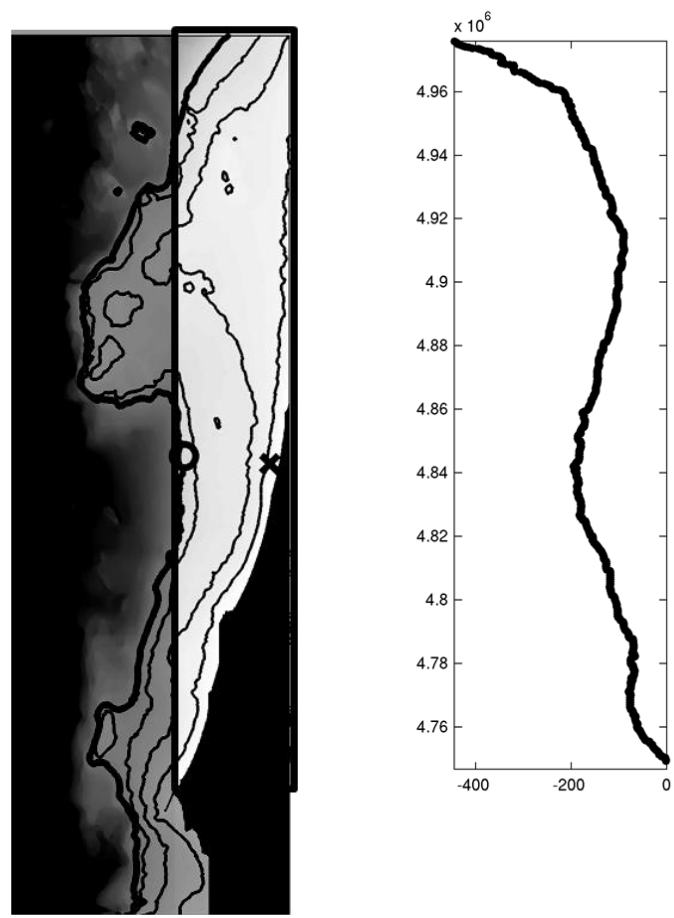

Figure 4 Left: Domain is cut with new offshore boundary at 46229. Right: Water depth (m) along offshore boundary of new smaller domain. 
We proposed two solutions to this problem. First, assume that the spectra measured at 46229 are a reasonable representation of the spectra along this new offshore boundary and force the entire boundary with this condition. An alternate solution would be to solve an inverse problem with the spectra measured at 46229 and find the associated deep water conditions. Once those conditions are found, the domain may be extended out into deep water and forced with this condition. The results in this paper use the first approach. In the future we hope to have results from the second approach for comparison.
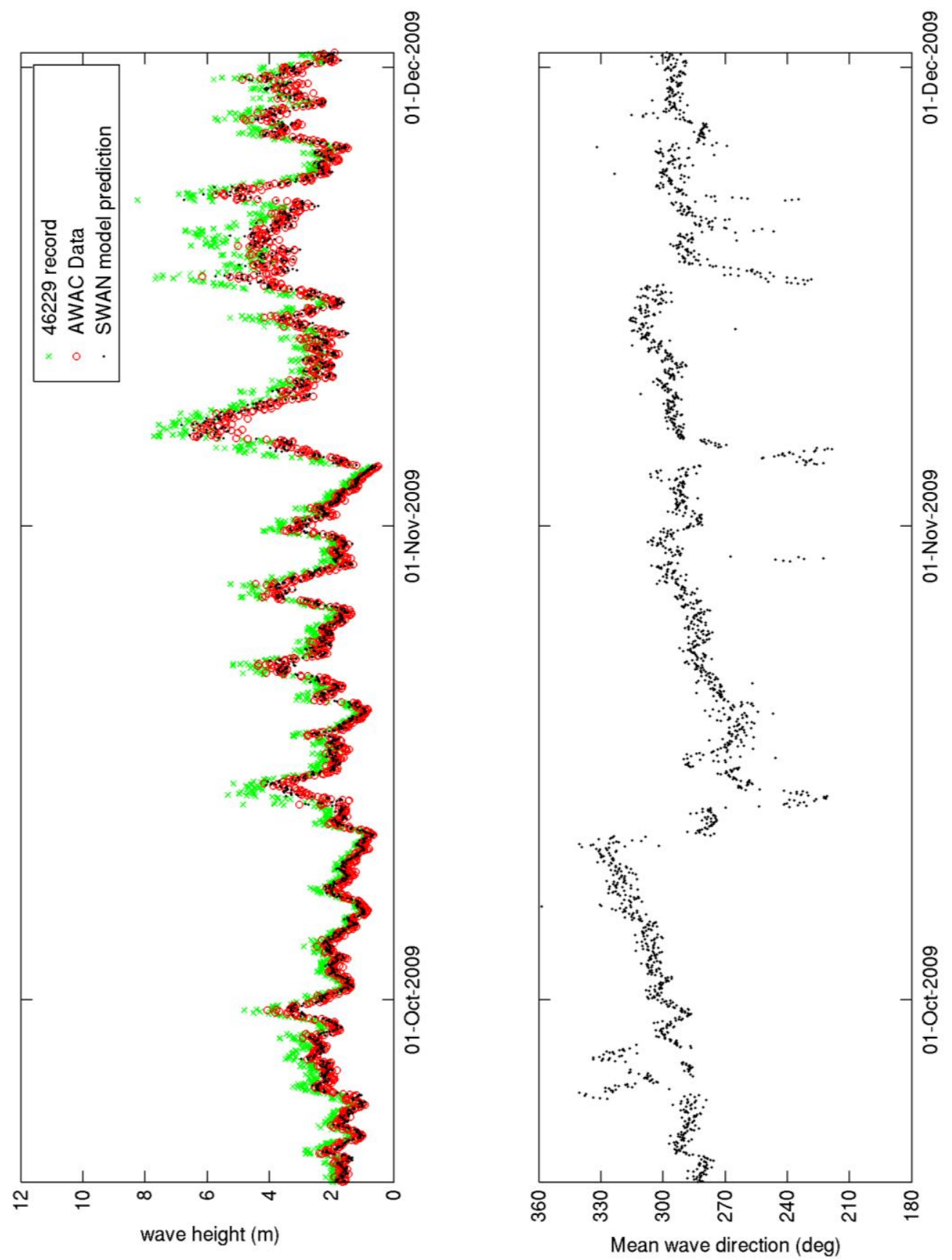

Figure 5 Top: Time series comparing model results to in situ wave height data: wave height $(\mathrm{m})$ ' $\mathrm{x}$ ' $=49229$, ' $O$ ' = in situ data, and '. ' = model Bottom: Mean wave direction (azimuth)

\section{Model Validation}

Using these assumptions with model input from 46229, hourly SWAN calculations were performed over the 2.5 months corresponding to the AWAC data. These results are shown in figure 5. This series shows the correlation between the predicted wave height at the WEC location and the measured wave 
height. The RMS error of the wave height predictions was 10 percent $(26 \mathrm{~cm})$, with an average error of -1 percent $(-3 \mathrm{~cm})$. We consider these very satisfactory for this type of model situation.

A closer look at a small portion of this time series will show the shadowing effects north of Cape Blanco. Figure 6 shows a four day time series where the mean wave direction begins from the west. Then, a storm arrives from the South and the mean wave direction is sharply to the south. Wave heights during this time show that for the westerly waves, the difference between the model input and output wave heights are small and fairly constant; however, when the direction changes to the south, the difference in wave height across the domain increases substantially.

\section{EFFECT OF A WEC ARRAY}

Until now, this paper has focused on the first of the three modeling domains mentioned at the very beginning, modeling the transformation of waves from offshore measurements to the WEC location. The second component involves characterizing the waves in and around a WEC array. For a very simple first model, we implemented SWAN with a very high resolution $(1 \mathrm{mx} 1 \mathrm{~m})$ and characterized the WECs as piles (figure 7). These piles are assumed to be rigid and extend through the entire water column. In this plot, they absorb 100 percent of the incident energy. It is obvious that conceptually piles are not an adequate substitution for floating WECs which most certainly have a very complex interaction with the surrounding waves. In spite of this, it is possible that SWAN results can be calibrated with observations to produce a useful and computationally efficient characterization of the wave field behind a WEC array. In the near future, we plan to use WAMIT (Lee, 1995) to solve the wave structure interaction problem with some more realistic assumptions. Both the SWAN model and WAMIT will be compared and calibrated with lab data from and experiment scheduled for October 2010.

The final step in the modeling problem to see the effects along the coastline is to add a third modeling domain shoreward of the first two and use the data from these to force it. Using the proposed SWAN models for the first and second domains and then also for the third domain, figure 8 displays the results of this third domain assembled with the others. Figure 8 shows a zoomed in view with the three different domains highlighted.
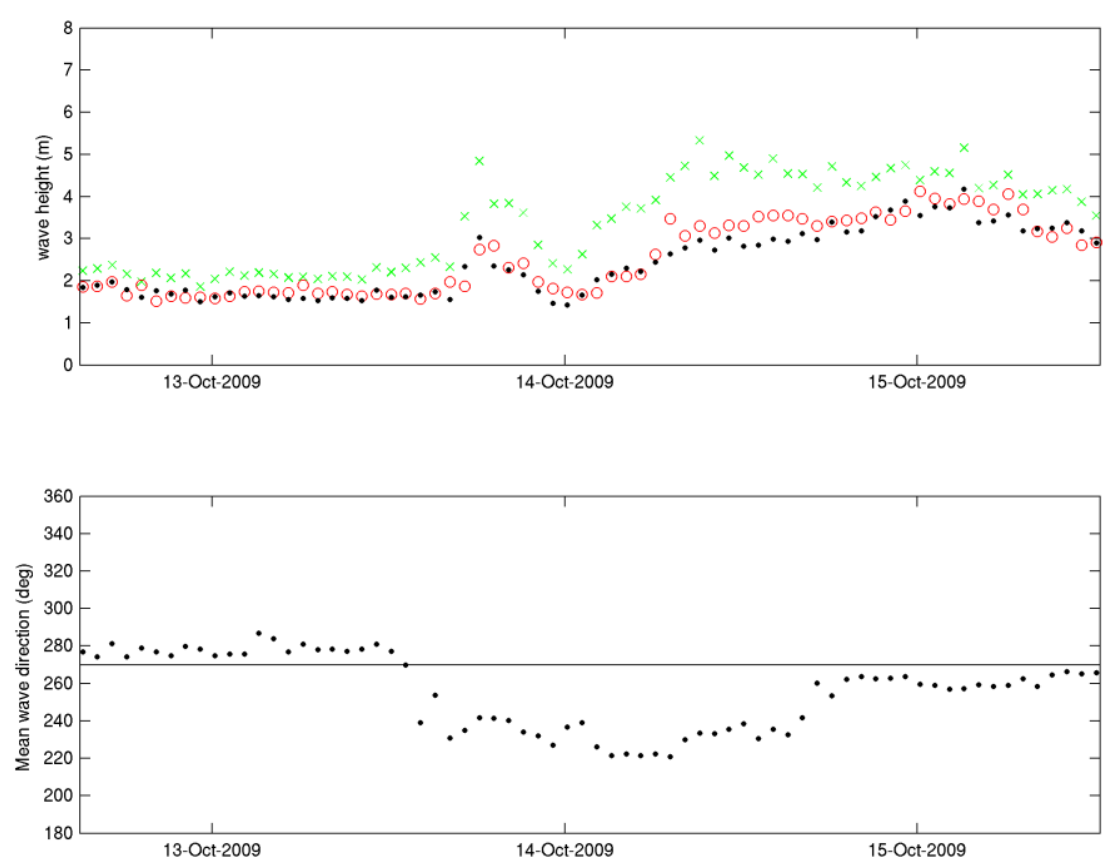

Figure 6 Short time series showing the shadowing effects north of Cape Blanco for southern incident waves. Top: wave height $(\mathrm{m})$ ' $\mathrm{x}$ ' = 49229, ' $\mathrm{o}$ ' = in situ data, and '. ' = model. Bottom: mean wave direction (Azimuth). 


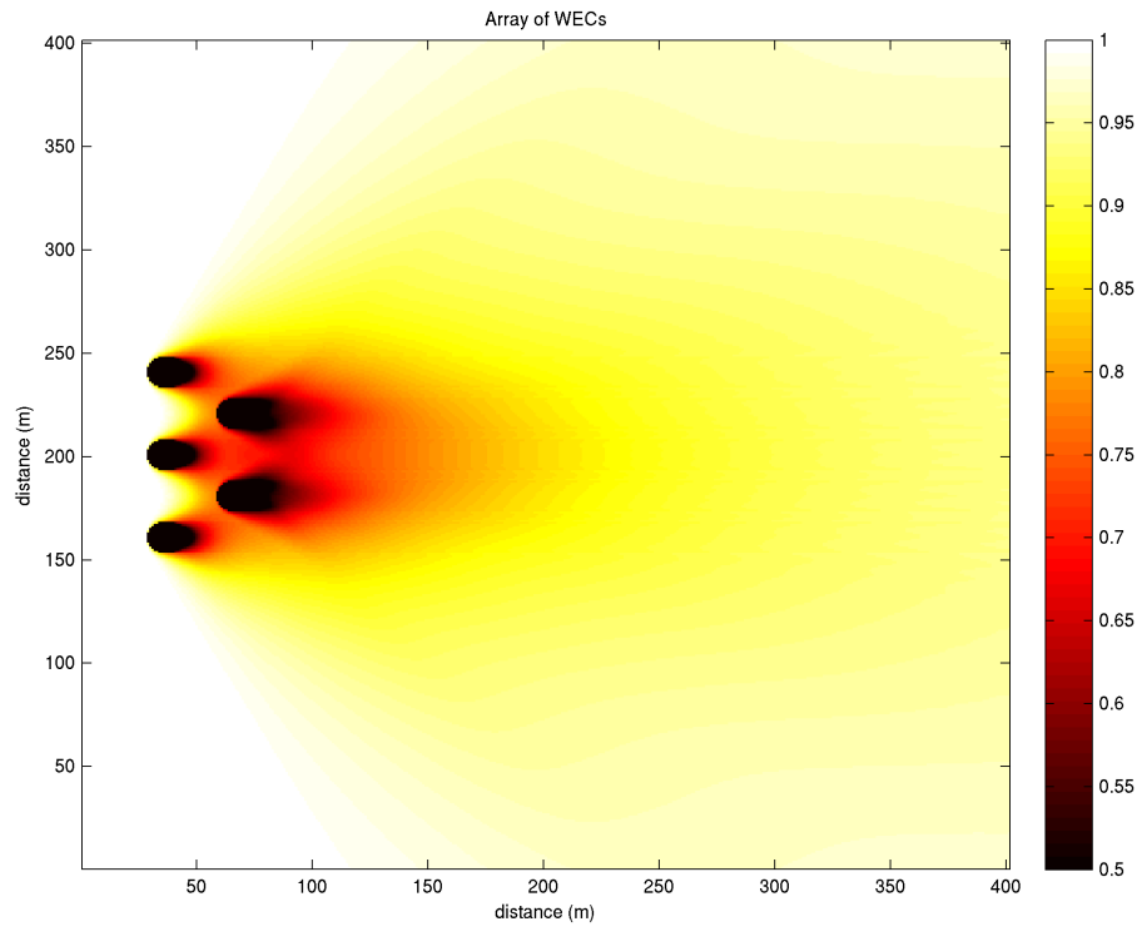

Figure 7 Wave heights: wake effects in the lee of a WEC array as modeled with SWAN.
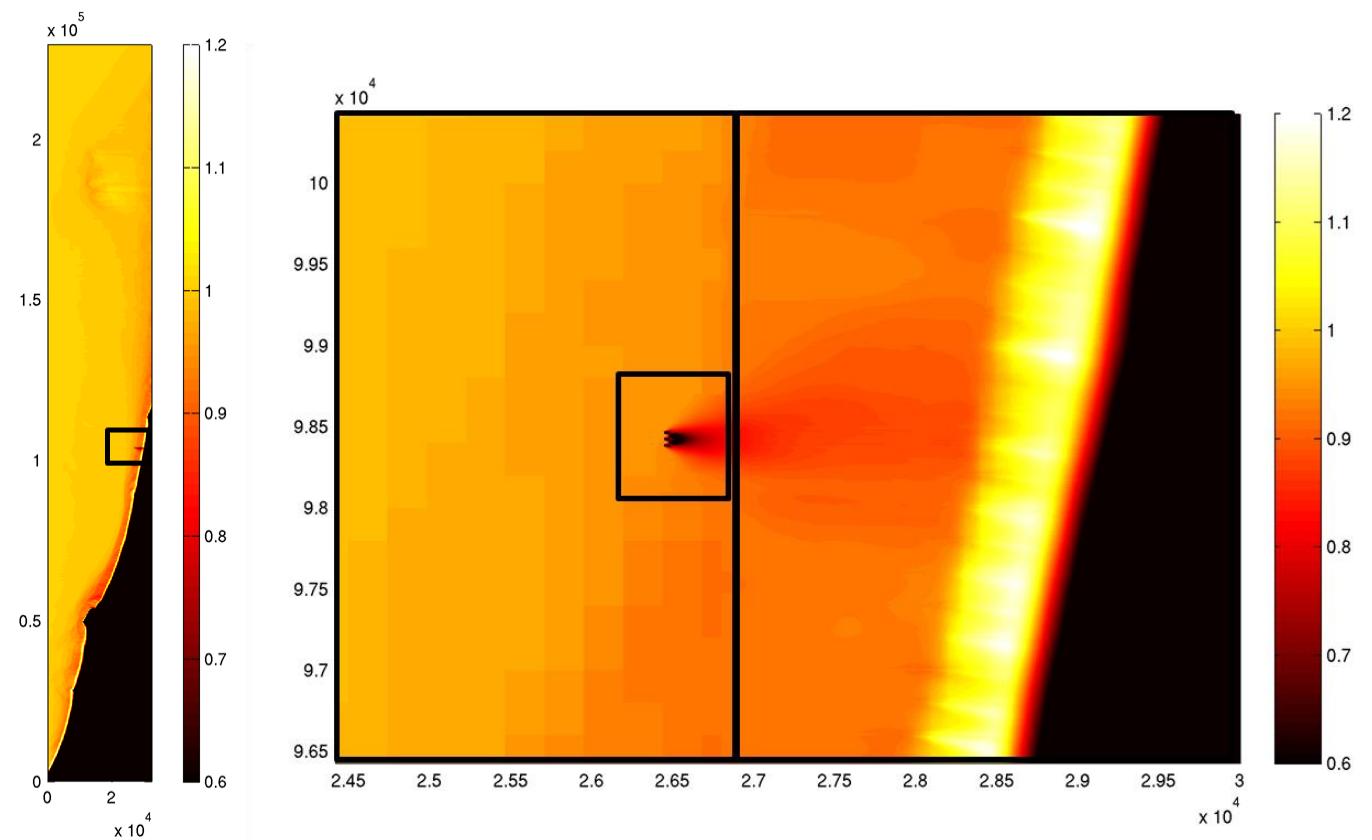

Figure 8 Left: Wake effects in the lee of a WEC array at the proposed WEC array site. Wave height (m). Right: zoomed region (area inside the box on the left figure) showing wake effects as they meet the shore line. The three model domains are boxed as in figure 1.

\section{CONCLUSIONS}

The SWAN model has proved to be skillful in our application when comparing with measured data, with an unbiased rms error of 10 percent predicting wave height compared to in situ data. This provides a good foundation to predict wave conditions at sites of potential WEC installations. A simple 
characterization of a WEC array was performed using SWAN, treating the WECs like piles. Future work should involve modeling the wave structure interaction problem with more realistic assumptions. These models will be calibrated with lab data from an experiment scheduled for October 2010. We show preliminary feasibility for propagate resulting waves to shore in the lee of an array using SWAN; however, further work is planned.

\section{ACKNOWLEDGMENTS}

The authors would like to thank John Barth, Ata Suanda, and Justin Brodersen for their field work collecting the in situ data used in this study. This paper is based upon work supported by the United States Department of Energy under award number DE-FG36-08G018179.

\section{REFERENCES}

Barstow, S. et al. 2003. WORLDWAVES- High quality coastal and offshore wave data within minutes for any global site, Proc. 2003 Int. Conference on Offshore Mechanics and Arctic Engineering, OMAE 2003, paper 37297.

Beels, C., P. Troch, G De Backer, M. Vantorre, J. De Rouck. 2010. Numerical implementation and sensitivity analysis of a wave energy converter in a time-dependent mild-slope equation model, Ocean Engineering, 57, 471-492.

Beels, C., P. Troch, K. De Visch, J. P. Kofoed, G. De Backer. 2010. Application of the time-dependent mild-slope equations for the simulation of wake effects in the lee of a farm of Wave Dragon wave energy converters, Renewable Energy, 35, 1644-1661.

Booij, N., R.C. Ris, and L.H. Holthuijsen. 1999. A thirdgeneration wave model for coastal regions: 1. Model description and validation, J. Geophys. Res., 104(C4), 7649-7666.

Dalrymple, R.A., J.T. Kirby. 1994. REF/DIF 1 Documentation and User's Manual, Center for Applied Coastal Research Report no 94-22, University of Delaware.

Kofoed, J.P., P. Frigaard, E. Friis-Madsen, H.C. Sorensen. 2006. Prototype testing of the wave energy converter wave dragon, Renewable Energy, 31, 181-189.

Lee, C.-H. 1995. WAMIT Theory Manual, Department of Ocean Engineering Report no 95-2, Massachusetts Institute of Technology.

Lenee-Bluhm, P. 2010. The Wave Energy Resource in the US Pacific Northwest, M.Sc., thesis, Oregon State University.

Millar, D.L., H.C.M. Smith, D.E. Reeve. 2007. Modelling analysis of the sensitivity of shoreline change to a wave farm, Ocean Engineering, 34. 884-901

Mørk, G., S. Barstow, A. Kabuth, M. T. Pontes. 2010 Assessing the global wave energy potential, Proc. of $29^{\text {th }}$ International Conference on Ocean, Offshore and Arctic Engineering, ASME, paper 20473.

Palha, Artur, L. Mendes, C. J. Fortes, A. Brito-Melo, A. Sarmento. 2010. The impact of wave energy farms in the shoreline wave climate: Portuguese pilot zone case study using Pelamis energy wave devices, Renewable Energy, 35, 66-77.

Yavuz, H., T. J. Stallard, A. P. McCabe, and G. A. Aggidis. 2006. Time series analysis-based adaptive tuning techniques for a heaving wave energy converter in irregular seas, Proc. IMechE Part A: Journal of Power and Energy, 221, 77-90. 